\title{
EFFECTS OF SUPPLEMENTATION WITH CREATINE MONOHYDRATE AND BETA-ALANINE, ALONE OR COMBINED, ON REPEATED SPRINT PERFORMANCE AND PHYSIOLOGICAL PARAMETERS IN AMATEUR TEAM AND RACKET SPORT PLAYERS
}

\author{
Anne Delextrat ${ }^{1}$, Nese Targen², Georgina Impson-Davey ${ }^{1}$, Daniel Kapsis ${ }^{1}$, James Bateman ${ }^{3}$, \\ Nicolas Terrados ${ }^{4}$, and Julio Calleja-González ${ }^{5}$ \\ ${ }^{1}$ Sport and Health Science Department, Oxford Brookes University, UK \\ ${ }^{2}$ Nutrition and Dietetics Department, Maidstone and Tunbridge Wells NHS Trust, UK \\ ${ }^{3}$ University College Birmingham, Birmingham, West Midlands, UK \\ ${ }^{4}$ Regional Sports Medicine Unit of Asturias, Aviles Municipal Sports Foundation \\ and Department of Functional Biology, University of Oviedo, Oviedo, Spain \\ ${ }^{5}$ Laboratory of Analysis of Sport Performance, Sport and Physical Education Department, \\ University of the Basque Country, Vitoria-Gasteiz, Spain
}

Original scientific article

DOI: $10.26582 / \mathrm{k} .52 .1 .15$

\begin{abstract}
:
The purpose of this study was to compare the combined effects of creatine monohydrate $(\mathrm{Cr})$ and betaalanine (BA) with their isolated use on performance and physiological parameters during repeated sprint sequences (RSS). Forty-four male $(\mathrm{n}=34)$ and female $(\mathrm{n}=10)$ amateur team- and racket sport players $(25.1 \pm 3.1$ years; $175.2 \pm 9.8 \mathrm{~cm} ; 76.0 \pm 10.3 \mathrm{~kg} ; 15.2 \pm 6.8 \%$ body fat) performed 10 repetitions of 6 -s sprints with departure every $30 \mathrm{~s}$, before and after a 28-day supplementation period with either $\mathrm{Cr}\left(\mathrm{n}=11 ; 5 \mathrm{~g} \cdot \mathrm{day}^{-1}\right), \mathrm{BA}(\mathrm{n}=10$; $\left.6 \mathrm{~g} \cdot \mathrm{day}^{-1}\right)$, combined $\mathrm{Cr}$ and BA $\left(\mathrm{n}=12 ; 5 \mathrm{~g} \cdot \mathrm{day}^{-1}\right.$ of Cr plus $6 \mathrm{~g} \cdot \mathrm{day}^{-1}$ of BA) or placebo $\left(\mathrm{n}=11 ; 11 \mathrm{~g} \cdot\right.$ day $^{-1}$ of $^{-}$ rice flour). Peak (PP) and mean power (MP), performance decrement (\%Dec), heart rate (HR), blood lactate concentration (LA), and perceived exertion (RPE) were measured. Analyses of variance (ANOVA) were used to determine the effects of groups (Cr, BA, CrBA, P), sprint number (1 to 10), and time (pre- vs. postsupplementation) on all variables. A significant increase in PP was shown in the post- compared to the pre-supplementation in $\mathrm{Cr}(+5.2 \%)$ and $\mathrm{BA}(+5.2 \%)$ groups only $(\mathrm{p}<.05)$, and significant decreases in MP in all groups $(3.7 \%$ to $6.4 \%, \mathrm{p}<.05)$, except BA. \%Dec was significantly decreased post-supplementation in the Cr group only $(17.4 \%, p<.05)$. No effects were shown on HR, RPE and LA $(p<.05)$. These results show no additional benefits of the combination of $\mathrm{Cr}$ and BA on RSS performance and suggest that longer sprint or total exercise duration might be necessary to observe the benefits of the combined supplementation.
\end{abstract}

Key words: lactate, power, recovery, short sprints, repeated sprint sequence

\section{Introduction}

Throughout a team or racket sport match, players are required to perform short maximal repeated sprints $(<6 \mathrm{~s})$, separated by brief recovery periods (20-25 s), during extended periods of time, defined as repeated sprint sequences (RSS) (Buchheit \& Laursen, 2013; Girard, Mendez-Villanueva, $\&$ Bishop, 2011). However, maximal sprint performance during RSS cannot be maintained for a very long time, as fatigue has been shown to develop as early as after the first sprint (Mendez-Villanueva, Hamer, \& Bishop, 2007). Multiple factors can cause fatigue during RSS, including limitations in anaerobic energy supply, metabolite accumulation in muscles and neural factors (Girard, et al., 2011).

During RSS, intramuscular $\mathrm{PCr}$ stores act as a short-term energy supply (Harris, Soderlund, \& Hultman, 1992). However, intramuscular PCr stores are limited and cannot be fully replenished during typical short recovery periods experienced in RSS (Gaitanos, Williams, Boobis, \& Brooks, 1993; Spencer, Bishop, Dawson, \& Goodman, 2005). Supplementation with creatine monohydrate $(\mathrm{Cr})$ has been shown to increase intramuscular $\mathrm{PCr}$ 
stores and increase the contribution of this source of energy to the total energy supply during RSS (Allen, Lamb, \& Westerblad, 2008; Balsom, Soderlund, Sjodin, \& Ekblom, 1995). Improvements in peak power and/or total mechanical work has been shown during RSS protocols including 6-12 sprint repetitions following the supplementation of $\mathrm{Cr}$ for six to 37 days, compared to a placebo (Kamber, et al., 1999; van Loon, et al., 2003; Yquel, Arsac, Thiaudiere, Canioni, \& Manier, 2002; Ziegenfuss, et al., 2002).

The progressive depletion of $\mathrm{PCr}$ during repeated sprints activates the anaerobic glycolysis pathway (Gaitanos, et al., 1993), leading to the intramuscular accumulation of $\mathrm{H}^{+}$if levels exceed removal via buffering. Muscle acidosis could have detrimental effects on muscle function, including inhibition of glycolytic enzymes, disruption in contractility and PCr resynthesis (Girard, et al., 2011; Spriet, Lindinger, McKelvie, Heigenhauser, \& Jones, 1989). Beta-alanine (BA) is the ratelimiting substrate for the intramuscular production of carnosine, one of the main intramuscular buffers (Hobson, Saunders, Ball, Harris, \& Sale, 2012). However, results on repeated efforts are equivocal with several studies showing no beneficial effect of four to five weeks following BA supplementation (6-6.4 g.day ${ }^{-1}$ ) compared to a placebo on RSS performance indicators (Ducker, Dawson, \& Wallman, 2013; Saunders, Sale, Harris, \& Saunderland, 2010; Sweeney, Wright, Brice, \& Doberstein, 2010), while significant improvements were shown with smaller doses but a similar supplementation duration on repeated knee extension strength (Derave, et al., 2007).

In view of the isolated benefits of $\mathrm{Cr}$ and $\mathrm{BA}$, a few studies have considered their potential combined effects, showing significant benefits on endurance (Zoeller, Stout, O'Kroy, Torok, \& Mielke, 2007) as well as single anaerobic performance (Hoffman, et al., 2006). Only two investigations have examined the combined effects of $\mathrm{Cr}$ and $\mathrm{BA}$ on long (30 s) repeated sprints, interspersed by 2-3-min of recovery (sprint interval training; SIT), showing contrasting results (Kresta, et al., 2014; Okudan, Belviranli, Pepe, \& Gokbel, 2015). Okudan et al. (2015) showed significant improvements in mean power in the combined group, compared to presupplementation in sedentary men, while Kresta et al. (2014) did not show any additive benefits of $\mathrm{BA}$ and $\mathrm{Cr}$ compared to their single use in recreationally active women when participants pedaled as fast as possible prior to the application of the workload and sprint at all-out maximal capacity during the 30-s test with 3-min of passive rest in between. However, to our knowledge, there is no study on the effect of this combination during shorter repeated sprint events, such as RSS. Results from SIT cannot be applied to RSS, as it is well- known that the contribution of different energy systems and limiting factors are different between these two types of intermittent exercises (Buchheit \& Laursen, 2013; Girard, et al., 2011). For example, blood lactate values are usually greater during SIT than RSS, and the smaller recovery experienced during RSS compared to SIT might slow down the restoration of PCr stores or lactate clearance (Buchheit \& Laursen, 2013).

Therefore, the main aim of this study was to compare the combined effects of $\mathrm{Cr}$ and BA with their isolated use on performance during RSS in team and racket sport players.

\section{Methods}

\section{Participants}

Fifty-two male $(n=40)$ and female $(n=12)$ amateur team and racket sport players were recruited from local clubs and university sport teams (Table 1). At the time of the study, they were involved in an average of 5-h of weekly training, including 2-h of resistance training and 3-h of aerobic-based exercise mixed with tactical work. Exclusion criteria were any known kidney or liver disease, lower limb injury, and use of nutritional supplements in the preceding four weeks. In addition, all participants were omnivores. They received detailed information about the study before giving informed written consent. Ethical approval for the study was granted by the university research ethics committee, in accordance with the Helsinki Board for the Protection of Human Subjects.

\section{Design}

This study used a randomized, double-blind, placebo-controlled, parallel group design.

\section{Methodology}

\section{Procedures}

All participants performed a familiarisation trial, and two main testing sessions, separated by a 28-day period of supplementation: a pre-supplementation trial (seven days after the familiarisation), and a post-supplementation trial (28 days after the pre-supplementation trial). Tests were undertaken towards the end of a regular competition season. Participants were randomly assigned to placebo (PLA, $\mathrm{n}=11$ ), creatine monohydrate only $(\mathrm{Cr}, \mathrm{n}=10)$, beta-alanine only (BA, $\mathrm{n}=11)$, or betaalanine plus creatine monohydrate $(\mathrm{BACr}, \mathrm{n}=12$ ) groups.

The familiarisation trial involved anthropometric measurements, including body height $(\mathrm{cm}$, Harpenden stadiometer, UK), body mass ( $\mathrm{kg}$ ) and body fat (\%, Tanita BC 418 MA, Tokyo, Japan). In addition, mid-thigh and calf girths were measured with a non-elastic tape measure (Harpenden, UK) 
Table 1. Subjects characteristics (mean $\pm S D$ ) in the placebo (PLA), creatine alone (Cr), beta-alanine alone (BA), and combined creatine and beta-alanine (BACr) groups (A. football: American football; $\triangle B L$ : delta blood lactate concentration)

\begin{tabular}{|c|c|c|c|c|c|}
\hline & PLA & $\mathrm{Cr}$ & BA & $\mathrm{BACr}$ & $\mathbf{p}$ \\
\hline Sample recruited - & $\begin{array}{c}9 \text { males } \\
2 \text { females }\end{array}$ & $\begin{array}{c}8 \text { males } \\
2 \text { females }\end{array}$ & $\begin{array}{c}8 \text { males } \\
3 \text { females }\end{array}$ & $\begin{array}{c}9 \text { males } \\
3 \text { females }\end{array}$ & - \\
\hline Sport & $\begin{array}{c}\text { soccer }(n=4) \\
\text { hockey }(n=2) \\
\text { A. football }(n=2) \\
\text { rugby }(n=1) \\
\text { netball }(n=1) \\
\text { squash }(n=1)\end{array}$ & $\begin{array}{c}\text { soccer }(n=3) \\
\text { hockey }(n=1) \\
\text { A. football }(n=1) \\
\text { rugby }(n=2) \\
\text { basketball }(n=2) \\
\text { badminton }(n=1)\end{array}$ & $\begin{array}{c}\text { soccer }(n=4) \\
\text { hockey }(n=2) \\
\text { A. football }(n=2) \\
\text { rugby }(n=1), \\
\text { lacrosse }(n=1) \\
\text { tennis }(n=1)\end{array}$ & $\begin{array}{c}\text { soccer }(n=5) \\
\text { hockey }(n=1) \\
\text { rugby }(n=1) \\
\text { netball }(n=1) \\
\text { tennis }(n=1) \\
\text { basketball }(n=2) \\
\text { volleyball }(n=1)\end{array}$ & - \\
\hline Drop-out (reasons) & $\begin{array}{c}\mathrm{n}=2 \text { (personal reasons) } \\
\text { and } \mathrm{n}=1 \text { (injury }{ }^{\#} \text { ) }\end{array}$ & $\mathrm{n}=1$ (injury $\left.{ }^{\#}\right)$ & $\mathrm{n}=2$ (paraesthesia) & $\mathrm{n}=2$ (injury ${ }^{\#}$ ) & \\
\hline Final sample & $\begin{array}{l}6 \text { males } \\
2 \text { females }\end{array}$ & $\begin{array}{l}7 \text { males } \\
2 \text { females }\end{array}$ & $\begin{array}{l}7 \text { males } \\
2 \text { females }\end{array}$ & $\begin{array}{l}8 \text { males } \\
2 \text { females }\end{array}$ & \\
\hline $\begin{array}{l}\text { Training } \\
\text { experience (years) }\end{array}$ & $5.2 \pm 1.6$ & $5.8 \pm 1.9$ & $4.4 \pm 2.1$ & $5.0 \pm 1.9$ & \\
\hline Age (years) & $25.2 \pm 1.6$ & $25.6 \pm 2.5$ & $24.2 \pm 2.2$ & $26.0 \pm 1.4$ & .545 \\
\hline Height (cm) & $174.9 \pm 8.9$ & $173.8 \pm 9.7$ & $176.0 \pm 8.0$ & $176.8 \pm 7.9$ & .477 \\
\hline Body mass (kg) & $\begin{array}{l}\text { Pre } 75.6 \pm 8.4 \\
\text { Post } 75.0 \pm 9.0\end{array}$ & $\begin{array}{l}\text { Pre } 74.7 \pm 6.6 \\
\text { Post } 77.3 \pm 6.8^{*}\end{array}$ & $\begin{array}{l}\text { Pre } 77.1 \pm 9.0 \\
\text { Post } 77.2 \pm 8.8\end{array}$ & $\begin{array}{l}\text { Pre } 76.4 \pm 9.2 \\
\text { Post } 77.3 \pm 8.9\end{array}$ & .032 \\
\hline Calf girth (cm) & $\begin{array}{l}\text { Pre } 35.3 \pm 2.4 \\
\text { Post } 35.1 \pm 1.9\end{array}$ & $\begin{array}{l}\text { Pre } 37.2 \pm 1.7 \\
\text { Post } 38.1 \pm 1.4\end{array}$ & $\begin{array}{l}\text { Pre } 36.7 \pm 1.5 \\
\text { Post } 37.0 \pm 1.5\end{array}$ & $\begin{array}{l}\text { Pre } 38.8 \pm 2.1 \\
\text { Post } 38.8 \pm 2.5\end{array}$ & .345 \\
\hline Thigh girth $(\mathrm{cm})$ & $\begin{array}{l}\text { Pre } 51.6 \pm 3.8 \\
\text { Post } 50.8 \pm 4.3\end{array}$ & $\begin{array}{l}\text { Pre } 52.2 \pm 4.2 \\
\text { Post } 53.4 \pm 4.1\end{array}$ & $\begin{array}{l}\text { Pre } 54.5 \pm 4.2 \\
\text { Post } 54.1 \pm 4.3\end{array}$ & $\begin{array}{l}\text { Pre } 55.5 \pm 4.0 \\
\text { Post } 55.0 \pm 3.9\end{array}$ & .242 \\
\hline Body fat (\%) & $\begin{array}{l}\text { Pre } 15.8 \pm 5.4 \\
\text { Post } 15.0 \pm 4.9\end{array}$ & $\begin{array}{l}\text { Pre } 14.7 \pm 6.1 \\
\text { Post } 14.9 \pm 5.9\end{array}$ & $\begin{array}{l}\text { Pre } 16.9 \pm 6.6 \\
\text { Post } 17.2 \pm 7.2\end{array}$ & $\begin{array}{l}\text { Pre } 14.8 \pm 7.6 \\
\text { Post } 15.5 \pm 8.4\end{array}$ & .714 \\
\hline $\begin{array}{l}\Delta \mathrm{BL} \\
\left(\mathrm{mmol} \cdot \mathrm{L}^{-1}\right)\end{array}$ & $\begin{array}{l}\text { Pre } 12.8 \pm 2.4 \\
\text { Post } 12.8 \pm 3.6\end{array}$ & $\begin{array}{l}\text { Pre } 14.1 \pm 3.2 \\
\text { Post } 14.2 \pm 3.4\end{array}$ & $\begin{array}{l}\text { Pre } 14.4 \pm 3.0 \\
\text { Post } 15.3 \pm 4.1\end{array}$ & $\begin{array}{l}\text { Pre } 12.5 \pm 2.9 \\
\text { Post } 13.6 \pm 3.4\end{array}$ & .276 \\
\hline
\end{tabular}

Note. *: significantly different from pre-supplementation values, $\mathrm{p}<.05$; \#: injuries were independent of the study.

according to the recommendations from the International Society for the Advancement of Kinanthropometry (ISAK). All these measures were taken by a qualified ISAK technician. Subsequently, subjects familiarised themselves with all procedures. To avoid diet-induced variability in exercise performance, all subjects were instructed to complete a 24-h food diary on the day before the first experimental trial and to replicate the same diet during the day before the second experimental trial. Furthermore, participants were instructed to abstain from strenuous exercise, alcohol and caffeine on the day preceding each experimental trial and to abstain from additional nutritional or performance enhancing supplements during the study.

\section{Dietary supplementation}

Participants were required to ingest 15 gelatine capsules a day (five at each main meal) for 28 days. Capsules contained either (a) $11 \mathrm{~g} \cdot$ day $^{-1}$ of riceflour (Doves Farm Rice Flour, Sainsbury's) in 15

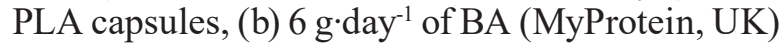
in seven BA capsules plus eight PLA capsules, (c) $5 \mathrm{~g} \cdot \mathrm{day}^{-1}$ of creatine monohydrate (MyProtein, UK) in eight $\mathrm{Cr}$ capsules plus seven PLA capsules, and (d) $6 \mathrm{~g} \cdot \mathrm{day}^{-1}$ of BA and $5 \mathrm{~g} \cdot \mathrm{day}^{-1}$ of $\mathrm{Cr}$ in seven BA capsules plus eight $\mathrm{Cr}$ capsules.

\section{Repeated sprint sequence (RSS) protocol}

The repeated sprint test protocol used in the present study consisted of ten maximal 6-s sprints on a cycle ergometer (Lode Excalibur Sport, Groningen, The Netherlands), interspersed by $24 \mathrm{~s}$ of passive recovery periods, against a load corresponding to $7.5 \%$ of participants' body mass (Bishop \& Spencer, 2004). Participants were verbally encouraged to produce maximal effort throughout the test. In addition, a criterion score assessment was performed before the main test, to avoid pacing (Bishop \& Spencer, 2004).

\section{Outcome measures}

The power averaged over the 6-s of each sprint was automatically computed (Lode Ergometry Manager software ${ }^{\circledR}$, Groningen, The Netherlands). Then, these values were used to calculate peak power (PP, in $\mathrm{W})$, defined as the maximal value over the ten sprints, and mean power (MP, in $\mathrm{W}$ ), calculated as the average power over the ten sprints. These values were then expressed relative to participants' body mass $\left(\mathrm{W} \cdot \mathrm{kg}^{-1}\right)$. Finally, performance decrement was also computed: $\%$ Dec $=100$ - $([$ mean power/peak power $]$ x 100) (Fitzimons, Dawson, Ward, \& Wilkinson, 1993). 
Heart rate $\left(\mathrm{HR}\right.$, in beats. $\left.\mathrm{min}^{-1}\right)$ was continuously measured during the test (Polar V800, Kemple, Finland), and averages during each 6-s sprint $\left(\mathrm{HR}_{\text {mean }}\right.$; beats $\left.\mathrm{min}^{-1}\right)$ and during the last 6-s of recovery following each sprint $\left(\mathrm{HR}_{\text {recov }}\right.$; beats $\left.\mathrm{min}^{-1}\right)$ were calculated. In addition, immediately after each sprint, subjects' rate of perceived exertion (RPE) was recorded using the Borg scale (Borg, 1982). Finally, approximately $5 \mu \mathrm{L}$ fingertip capillary blood samples were collected from fingertips at rest and within one minute after the completion of sprint 10. They were analysed for blood lactate concentration (LA, Lactate Pro 2, Arkray, Japan), and the difference between rest and post-exercise was calculated $\left(\Delta \mathrm{LA}\right.$, in $\left.\mathrm{mmol} \cdot \mathrm{L}^{-1}\right)$.

\section{Statistical analyses}

All data are reported as mean \pm standard deviation (SD). The Shapiro-Wilks test indicated normal distributions, and consequently a one-way analysis of variance (ANOVA) was used to examine differences between groups in baseline characteristics (age, body height, body mass, and \%body fat). In addition, ANOVAs with repeated measures followed by Bonferroni pairwise comparisons were performed to assess the effect of groups, time and sprint number (the latter only for HR and RPE) on outcome variables. The level of significance was set at $p<.05$. Effect sizes were calculated using partial eta squared $\left(\mathrm{\eta}_{\mathrm{p}}^{2}\right)$ and Cohen's $d(\mathrm{~d})$ and interpreted according to Cohen (1988).

\section{Results}

\section{Performance variables}

No significant differences between the groups were shown before the supplementation for any of the variables $(\mathrm{p}>.05)$.

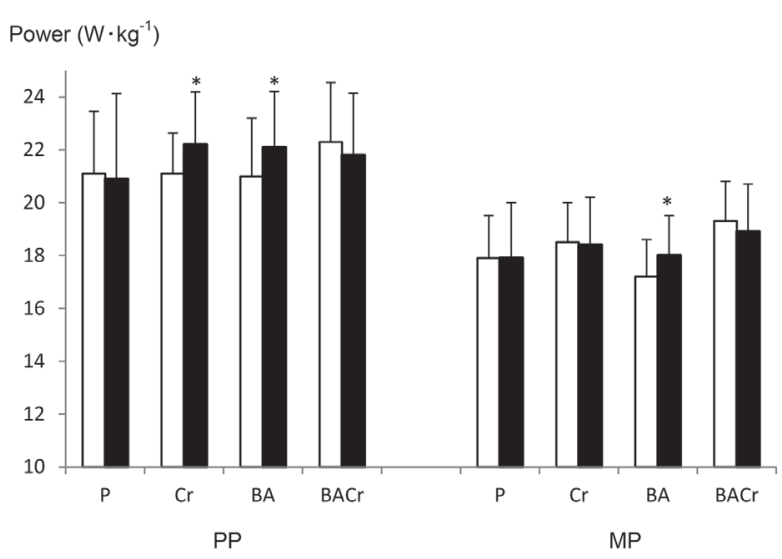

Note. *: significantly different from pre-supplementation, $p<.05$.

Figure 1. Differences in peak power (PP) and mean power (MP) between the pre- (white) and post-(black) supplementation periods (P: placebo; Cr: creatine; BA: beta-alanine; BACr: creatine and beta-alanine combination).
The statistical analysis showed a significant effect of time ( $\left.\mathrm{p}=.006, \mathrm{\eta}_{\mathrm{p}}^{2}=0.179\right)$ and interaction between time and group $\left(\mathrm{p}=.049, \mathrm{\eta}_{\mathrm{p}}^{2}=0.180\right)$ on PP. Significant increases in PP in the post- compared to the pre-supplementation periods were observed in the $\mathrm{Cr}(+5.2 \%, \mathrm{p}=.014, \mathrm{~d}=0.62,95 \%$ CI: 0.10 to $\left.1.88 \mathrm{~W} \cdot \mathrm{kg}^{-1}\right)$ and $\mathrm{BA}(+5.3 \%, \mathrm{p}=.010, \mathrm{~d}=0.50,95 \%$ CI: 0.35 to $1.96 \mathrm{~W} \cdot \mathrm{kg}^{-1}$ ) groups only (Figure 1). In contrast, no significant increase in PP was observed in the $\mathrm{P}$ and $\mathrm{BACr}$ groups.

Despite no significant effect of time ( $\mathrm{p}=.144$, $\left.\eta_{\mathrm{p}}^{2}=0.053\right)$ or group $\left(\mathrm{p}=.294, \eta_{\mathrm{p}}^{2}=0.090\right)$ on MP, a significant interaction between these factors was shown $\left(\mathrm{p}=.046, \mathrm{\eta}_{\mathrm{p}}^{2}=0.180\right)$. Post-hoc comparisons showed a significant increase in MP in the BA group only $(+4.7 \%, p=.023, d=0.52,95 \% \mathrm{CI}$ : 0.48 to $1.55 \mathrm{~W} \cdot \mathrm{kg}^{-1}$, Figure 1). Finally, no significant effect of time $\left(\mathrm{p}=.059, \mathrm{\eta}_{\mathrm{p}}^{2}=0.095\right)$, group $(\mathrm{p}=.310$, $\left.\eta_{\mathrm{p}}^{2}=0.087\right)$, or their interaction $\left(\mathrm{p}=.169, \mathrm{\eta}_{\mathrm{p}}^{2}=0.120\right)$ was observed on $\% \mathrm{Dec}$, with values ranging from $11.9 \pm 3.9 \%$ to $15.0 \pm 6.3 \%$ in the pre-test, and from $13.6 \pm 6.6$ to $18.6 \pm 6.0$ in the post-test. Figure 2 shows the profile of power outputs for each group in the pre- and post-tests.

\section{Physiological, anthropometric, and perceptual variables}

No significant effect of time $\left(\mathrm{p}=.276, \eta_{\mathrm{p}}^{2}=0.033\right)$, group $\left(\mathrm{p}=.357, \eta_{\mathrm{p}}^{2}=0.085\right)$, or time* group interaction $\left(\mathrm{p}=.773, \mathrm{\eta}_{\mathrm{p}}^{2}=0.030\right)$ was observed on $\Delta \mathrm{LA}$ and calf or thigh girths (Table 1). A significant effect of sprint number only was shown on RPE ( $\mathrm{p}=.001$, $\left.\eta_{\mathrm{p}}^{2}=0.854\right)$, with RPE significantly increasing with each sprint (RPE ranging from $11.1 \pm 2.9$ to $13.2 \pm 2.7$ in sprint 1 to $18.2 \pm 1.2$ to $19.1 \pm 1.0$ in sprint 10 , $\mathrm{p}=.001$ ).

A significant effect of sprint number $(\mathrm{p}=.001$, $\left.\eta_{\mathrm{p}}^{2}=0.658\right)$ and the interaction between sprint number, group, and time $\left(\mathrm{p}=.023, \mathrm{n}_{\mathrm{p}}^{2}=0.121\right)$ were shown on $\mathrm{HR}_{\text {mean }}$. In the PLA, BA, and BACr groups, significant effects of sprint number only were observed $\left(\mathrm{p}=.001, \mathrm{\eta}_{\mathrm{p}}^{2}=0.648\right.$ to 0.683 ). However, the Cr group was characterised by significant effects of sprint number ( $\mathrm{p}=0.001, \mathrm{\eta}_{\mathrm{p}}^{2}=0.686$ ), as well as the interaction between sprint number and time $(p=.001$, $\eta_{\mathrm{p}}^{2}=0.421$ ). A significant effect of sprint number was shown on $\mathrm{HR}_{\text {recov }}\left(\mathrm{p}=.001, \mathrm{\eta}_{\mathrm{p}}^{2}=0.733\right)$. Pairwise comparisons between sprints in each condition for both variables are shown in Figures 3-a to 3-d.

\section{Discussion and conclusions}

The main findings of the present study were the significant positive effects of $\mathrm{Cr}$ alone on peak power and BA alone on peak and mean power. The greater power outputs observed occurred without any significant differences in physiological parameters measured between the groups. However, we did not observe any significant additional benefits 

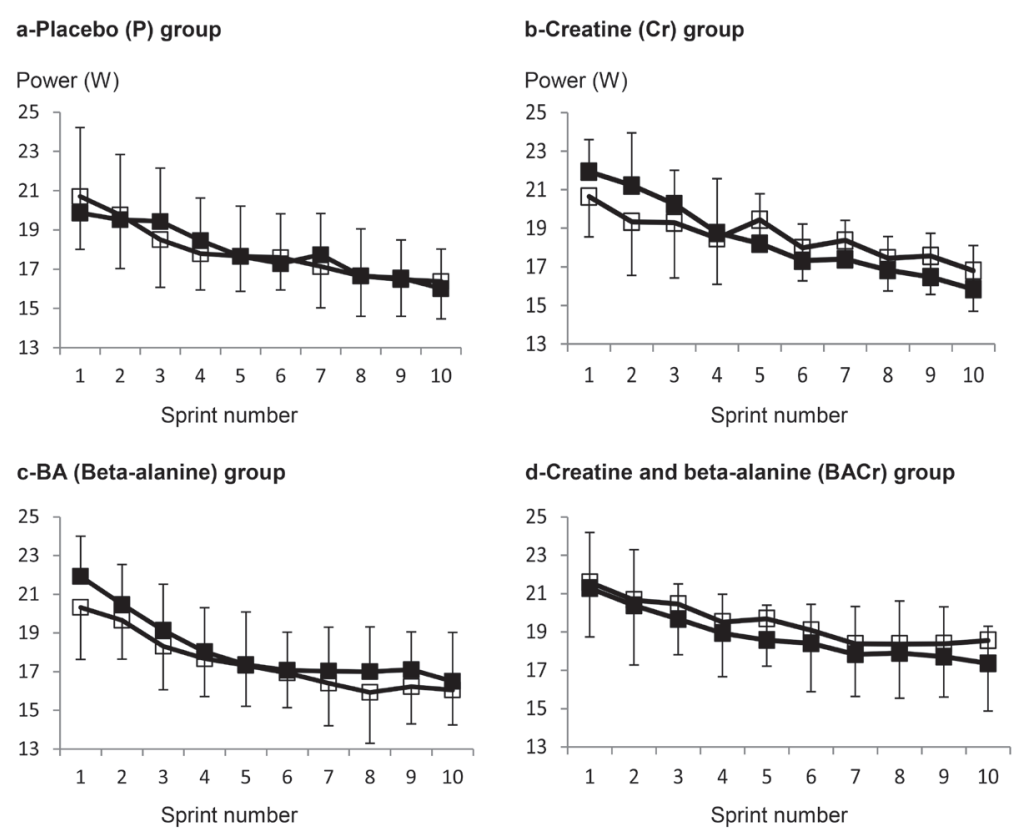

Figure 2. Power output for each sprint of the RSS test in the pre-(empty symbols) and post-(filled symbols) supplementation periods in the $\mathrm{P}(a), \mathrm{Cr}(b), B A(c)$ and $B A C r(d)$ groups.

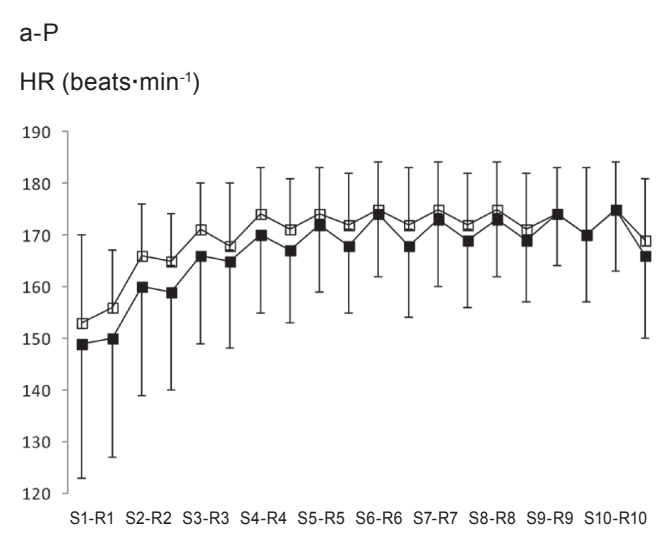

HRmean: significant differences between $\mathrm{S} 1$ and $\mathrm{S} 3$ to $\mathrm{S} 8$, between $\mathrm{S} 2$ and $\mathrm{S} 3$ to $\mathrm{S} 7$, and between $\mathrm{S} 3$ and $\mathrm{S} 6, \mathrm{p}<.05$

HRrecov: significant differences between $\mathrm{S} 1$ to $\mathrm{S} 2$ and all the others; between $\mathrm{S} 3$ and all but S10; between S4 and all but S9 and S10; and between S8 to S9 and $\mathrm{S} 10, \mathrm{p}<.05$.

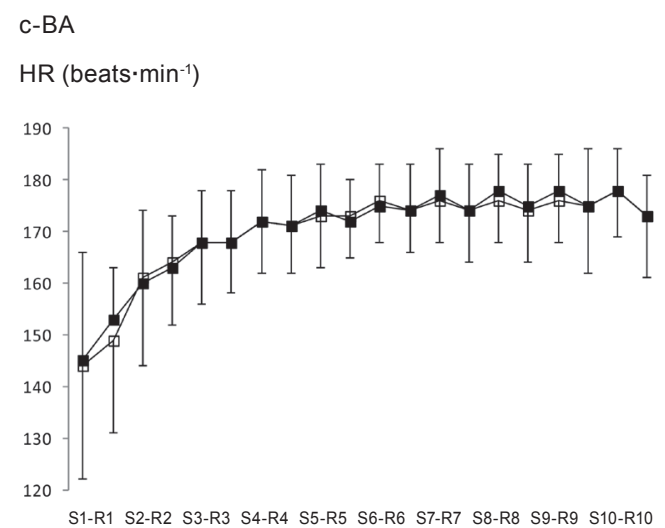

HRmean: significant differences between $\mathrm{S} 1$ and $\mathrm{S} 4$ to $\mathrm{S} 7$; between $\mathrm{S} 5$ and $\mathrm{S} 6$, $\mathrm{p}<.05$.

HRrecov: significant differences between $\mathrm{S} 1$ to $\mathrm{S} 2$ and all the others; between $\mathrm{S} 3$ and all but S10; between S4 and all but S9 and S10; and between S8 to S 9 and $\mathrm{S} 10, \mathrm{p}<.05$.

Figure 3. Heart rate during $\left(H R_{\text {mean }}\right)$ and after $\left(H R_{\text {recov }}\right)$ each sprint of the RSS test in the pre- (empty symbols) and post- (full symbols) supplementation periods. S1 to S10: sprints 1 to 10; R1 to R10: recovery periods after sprints 1 to 10.

\section{$\mathrm{b}-\mathrm{Cr}$}

$\mathrm{HR}\left(\right.$ beats $\left.\cdot \mathrm{min}^{-1}\right)$

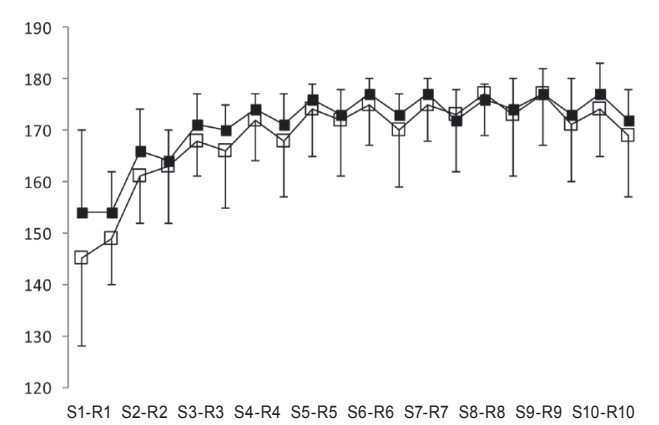

HRmean: Pre-supplementation: significant differences between $\mathrm{S} 1$ and $\mathrm{S} 5$ to $\mathrm{S} 6$, $\mathrm{p}<.05$. Post-supplementation: significant differences between S1 and S3 to S9, and between S3 and S5 and S7 to S8, p<.05

HRrecov: significant differences between $\mathrm{S} 1$ to $\mathrm{S} 2$ and all the others; between $\mathrm{S} 3$ and all but $\mathrm{S} 10$; between $\mathrm{S} 4$ and all but $\mathrm{S} 9$ and $\mathrm{S} 10$; and between $\mathrm{S} 8$ to $\mathrm{S} 9$ and $\mathrm{S} 10, \mathrm{p}<.05$.

\section{d-BACr}

HR (beats $\cdot \min ^{-1}$ )

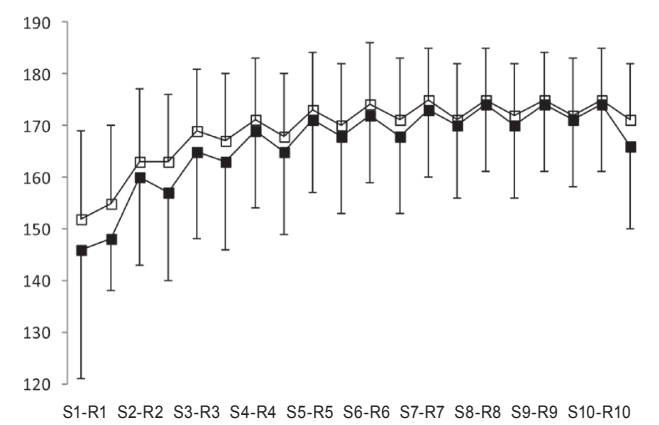

HRrecov: significant differences between $\mathrm{S} 1$ to $\mathrm{S} 2$ and all the others; between $\mathrm{S} 3$ and all but S10; between S4 and all but S9 and S10; and between S8 to S 9 and $\mathrm{S} 10, \mathrm{p}<.05$.
HRmean: significant differences between $\mathrm{S} 1$ and all the others, $p<.05$. 
of the combination of $\mathrm{Cr}$ and $\mathrm{BA}$, compared to their isolated use, on repeated sprint performance in team and racket sport players.

Significant increases in PP were observed in the post- compared to the pre-supplementation test in the $\mathrm{Cr}(+5.2 \%)$ and BA $(+5.3 \%)$ groups only, both accompanied by moderate effect sizes. These results are similar to those of Yquel et al. (2002), showing a 5\% increase in peak-power output in bouts 3-7 of a 7-bout intermittent-sprint protocol (8-16-s sprints) following a 6-day $\mathrm{Cr}$ loading protocol $\left(20 \mathrm{~g} \cdot \mathrm{day}^{-1}\right)$, compared to a control condition in healthy men. In addition, van Loon et al. (2003) used a longer supplementation period (five days loading at $20 \mathrm{~g} \cdot \mathrm{day}^{-1}$ and six weeks at $2 \mathrm{~g} \cdot \mathrm{day}^{-1}$ ) and observed a significant increase in PP in seven out of the 12 sprints of a twelve 12-s intermittent-sprint protocol. These increases in PP following Cr supplementation are likely to be due to an increase in muscle creatine stores, as it has been shown that resting muscle creatine stores can be increased by up to $20 \%$ via exogenous supplementation (Allen, et al., 2008). Intramuscular $\mathrm{Cr}$ stores have been shown to be reduced by $57 \%$ and $83 \%$, respectively, after the first and the last sprint of a 10x6 second (30-s recovery) repeated-sprint protocol (Gaitanos, et al., 1993). Unfortunately, no measure of intramuscular Cr was obtained in the present study; however, body mass was significantly increased and there was a trend for greater thigh girth measures in the postcompared to the pre-supplementation in the $\mathrm{Cr}$ group only. Increased body mass after $\mathrm{Cr}$ supplementation protocols is commonly observed in literature and usually accounted for by a rise in fat free mass (e.g., van Loon, et al., 2003). The effects of BA on PP during RSS show more contrasting results in literature, with no significant effect observed during short intermittent sprint protocols, eg. $5 \times 5$-s and 6x20-m running sprints (Ducker, et al., 2013; Sweeney, et al., 2010), but significant improvements in PP were observed during longer SIT protocols (4x30-s upper body Wingate tests each separated by 3-min rest periods; Tobias, et al., 2013). One explanation for the significant effect of BA on PP in the present study could be that our sprint duration and number of repetitions were slightly greater than the short sprints described above. Furthermore, it has been suggested that, in addition to its buffering benefits, BA increases calcium sensitivity in contractile fibres (Hobson, et al., 2012), which could in turn result in a greater PP. However, these mechanisms have not been fully determined, and hence further studies are necessary to investigate the effects of BA on RSS.

In the present study, MP was significantly improved in the BA group only $(+4.7 \%)$, with a moderate effect size. In addition, no significant difference in $\%$ Dec was observed in any group. In the context of team or racket sports, the greater PP and MP in the BA group in the post- compared to the pre-supplementation suggests that this type of supplementation is better than $\mathrm{Cr}$ (increase in PP but no change in MP or \%Dec) or BACr (no variation in $\mathrm{PP}, \mathrm{MP}$, or $\% \mathrm{Dec}$ ) because it would not only increase the quality of sprints at the start of a match, but it would also maintain performance throughout the match. This can be illustrated on the power profiles shown in Figure 2, where the only condition where the post-supplementation powers are over the pre-supplementation powers in the second part of the test is the BA condition. However, the application of our findings to team and racket sports is somewhat limited by the fact that we used a cycling repeated sprint protocol. Literature presents contrasting results about the effects of BA on repeated sprint performance. For instance, a recent study by Tobias et al. (2013) found a significant effect of BA on the mean power in the 2 nd and 3 rd bouts of a $4 \times 30-s$ upper body Wingate tests each separated by 3 -min rest periods in competitive judo and jiu-jitsu athletes. In contrast, other studies using shorter sprint times found similar results to the present study, with no significant effect of BA supplementation on MP or \%Dec (Ducker, et al., 2013; Sweeney, et al., 2010). In addition, results from a meta-analysis suggested that BA does not affect exercise performance in exercises lasting less than 60-s (Hobson, et al., 2012). The benefits of BA supplementation on repeated sprint performance are classically attributed to the buffering of $\mathrm{H}^{+}$ions during the recovery between bouts by carnosine inside the muscle fibre. Indeed, Harris et al. (2006) reported a $64 \%$ increase in intramuscular carnosine levels following a 4-week supplementation period with $6.4 \mathrm{~g} \cdot \mathrm{d}^{-1}$ of BA. Therefore, sprint duration of 6 -s in the present study might not have been sufficient to stimulate the anaerobic glycolysis energy system and produce enough lactate and $\mathrm{H}^{+}$ions, and our recovery might not have been long enough to allow enough buffering to take place. Within this context, in their review of high-intensity interval training, Buchheit and Laursen (2013) highlighted that blood lactate concentration during RSS protocols similar to the present study were lower than during protocols including longer sprints, such as SIT (6-18 mmol $\left.\cdot \mathrm{L}^{-1} v s .16-22 \mathrm{mmol} \cdot \mathrm{L}^{-1}\right)$. The delta blood lactate values obtained in the present study are in accordance with this hypothesis, with no significant difference between the groups, and values from 12.8 to 15.3 obtained amongst conditions (resting blood lactate lower than $2.0 \mathrm{mmol} \cdot \mathrm{L}^{-1}$ ). However, there was a trend for an increase in blood lactate between the pre- and the post-supplementation periods in the $\mathrm{BA}$ and $\mathrm{BACr}$ groups only.

Interestingly, despite the benefits of both $\mathrm{Cr}$ and $\mathrm{BA}$ on PP, and of BA on MP, the combination of these ergogenic aids not only did not result in any significant improvement in PP and MP, but proved 
to be worse than each substance implemented isolated. To our knowledge, our study is the first to investigate the potential benefits of this combination on RSS performance. Our results are in accordance with those of studies focusing on longer sprints, either continuous (mechanical work during a sprint at $110 \%$ of maximal power; Hill, et al., 2005), or intermittent (two or three repeated 30-s Wingates; Kresta, et al., 2014; Okudan, et al., 2015), showing significant benefits of $\mathrm{Cr}$ or $\mathrm{BA}$, but no additional positive effects of the combination of these supplements. However, comparisons with literature are difficult due to the different doses and administration protocols (loading, maintenance periods). There is no physiological reason why $\mathrm{Cr}$ and $\mathrm{BA}$ would be counteractive to each other (Harris, et al., 2006). Therefore, the lack of positive effect of the $\mathrm{BACr}$ combination on performance variables in the present study could be due to the inter-individual variability in response to the $\mathrm{BA}$ and $\mathrm{Cr}$ supplementation, with maybe more participants with a low response to these supplements in the BACr group, compared to the $\mathrm{Cr}$ and $\mathrm{BA}$ groups. For example, around 20 to $30 \%$ of individuals who undergo $\mathrm{Cr}$ supplementation do not increase their muscle $\mathrm{Cr}$ stores (Greenhaff, 1997). Exercise and recovery duration may be another potential reason for the lack of significant differences in the BACr group. Zoeller et al. (2007) showed that BACr significantly improved five out of eight indices of cardiorespiratory endurance during an incremental test, including oxygen consumption and power output at the ventilatory and lactate thresholds, while the sole use of Cr or BA was less beneficial. In RSS, the aerobic system is used to replenish $\mathrm{PCr}$ stores and metabolise lactate during the recovery between sprints. Therefore, we could hypothesize a greater oxidative capacity after the BACr supplementation that could result in improved RSS performance, as
RSS performance has been correlated to aerobic capacity (Girard, et al., 2011). Therefore, recovery periods (24-s) between the sprints might not have been long enough for a maximal involvement of the aerobic system to restore $\mathrm{PCr}$ stores or clear lactate. In favour of this hypothesis, a similar study by Kamber et al. (1999), which involved longer recovery periods than 24 -s (i.e. $30-$ s) found $7 \%$ improvement in performance in the late phases of repeated sprints (10x6-s) following $\mathrm{Cr}$ supplementation. Finally, we cannot exclude a potential effect of fatigue or overtraining in some of our participants, since testing was undertaken towards the end of the season.

The main limitations of the present study were a rather small sample size and relatively high dropout rate; however these numbers are expected in 4-week long studies and our sample was similar or greater than in other studies in this area (e.g., Kresta, et al., 2014). In addition, measuring the amount of creatine or carnosine in muscles would have helped interpret our findings. Finally, the extrapolation of our findings to team and racket sports is limited by the fact that our protocol was performed on a bicycle ergometer.

In conclusion, our main results did not show any significant additional benefits of the combination of $\mathrm{Cr}$ and $\mathrm{BA}$, compared to their isolated use on RSS. However, the positive effects of $\mathrm{Cr}$ alone on PP as well as BA alone on PP and MP highlight that these substances are ergogenic for these types of sports when consumed in isolation. While the combination of $\mathrm{Cr}$ and $\mathrm{BA}$ might be recommended for longer repeated sprints or endurance events, it may not be for short repeated sprints characteristic of team and racket sports. Further studies should be undertaken to understand the mechanisms involved in the effects of BA, particularly on performance during RSS. 


\section{References}

Allen, D.G., Lamb, G.D., \& Westerblad, H. (2008). Skeletal muscle fatigue: Cellular mechanisms. Physiological Reviews, 88(1), 287-332. doi: 10.1152/physrev.00015.2007

Balsom, P., Soderlund, K., Sjodin, B., \& Ekblom, B. (1995). Skeletal muscles metabolism during short duration high intensity exercise. Acta Physiologica Scandinavica, 154, 303-310. doi: 0.1111/j.1748-1716.1995.tb09914

Bishop, D., \& Spencer, M. (2004). Determinants of repeated-sprint ability in well-trained team-sport athletes and endurance-trained athletes. Journal of Sports Medicine and Physical Fitness, 44(1), 1-7.

Borg, G.A. (1982). Psychophysical bases of perceived exertion. Medicine and Science in Sports and Exercise, 14, $377-381$.

Buchheit, M., \& Laursen, P.B. (2013). High-intensity interval training, solutions to the programming puzzle. Part II: Anaerobic energy, neuromuscular load and practical applications. Sports Medicine, 43(10), 927-954. doi: 10.1007/s40279-013-0066-5

Cohen, J. (1988). Statistical power for the behavioral sciences (2 ${ }^{\text {nd }}$ ed.). Hillsdale, NJ: Lawrence Earlbaum Associates.

Derave, W., Özdemir, M.S., Harris, R.C., Pottier, A., Reyngoudt, H., Koppo, K., ..., \& Achten, E. (2007). B-alanine supplementation augments muscle carnosine content and attenuates fatigue during repeated isokinetic contraction bouts in trained sprinters. Journal of Applied Physiology, 103, 1736-1743. doi: 10.1152/japplphysiol.00397.2007

Ducker, K.J., Dawson, B., \& Wallman, K.E. (2013). Effect of beta alanine and sodium bicarbonate supplementation on repeated-sprint performance. Journal of Strength and Conditioning Research, 27(12), 3450-3460. doi: 10.1519/ JSC.0b013e $31828 \mathrm{fd} 310$

Fitzimons, M., Dawson, B., Ward, D., \& Wilkinson, A. (1993). Cycling and running tests of repeated sprint ability. Australian Journal of Science and Medicine in Sport, 25, 82-87.

Gaitanos, G.C., Williams, C., Boobis, L.H., \& Brooks, S. (1993). Human muscle metabolism during intermittent maximal exercise. Journal of Applied Physiology, 75, 712-719.

Girard, O., Mendez-Villanueva, A., \& Bishop, D. (2011). Repeated-sprint ability-Part I: Factors contributing to fatigue. Sports Medicine, 41(8), 673-694. doi: 10.2165/11590550-000000000-00000

Greenhaff, P.L. (1997). Nutritional biochemistry of creatine. Journal of Nutrition and Biochemistry, 8(11), 610-618.

Harris, R.C., Soderlund, K., \& Hultman, E. (1992). Elevation of creatine in resting and exercised muscle of normal subjects by creatine supplementation. Clinical Science, 83(3), 367-374.

Harris, R.C., Tallon, M.J., Dunnett, M., Boobis, L., Coakley, J., \& Kim, H.J. (2006). The absorption of orally supplied beta-alanine and its effect on muscle carnosine synthesis in human vastus lateralis. Amino Acids, 30(3), $279-289$. doi: 10.1007/s00726-006-0299-9

Hill, C.A., Harris, R.C., Kim, H.J., Boobis, L., Sale, C., \& Wise, J.A. (2005). The effect of beta-alanine and creatine monohydrate supplementation on muscle composition and exercise performance. In Proceedings of the 52nd Annual Meeting of the American College of Sports Medicine, Tennessee, USA. Medicine and Science in Sports and Exercise, 37(5), S348.

Hobson, R.M., Saunders, B., Ball, G., Harris, R.C., \& Sale, C. (2012). Effects of B-alanine supplementation on exercise performance: A meta-analysis. Amino Acids, 43, 25-37. doi: 10.1007/s00726-011-1200-z

Hoffman, J.R., Ratamess, N.A., Kang, J., Mangine, G., Faigenbaum, A.D., \& Stout, J. (2006). Effect of creatine and B-alanine supplementation on performance and endocrine responses in strength/power athletes. International Journal of Sport Nutrition and Exercise Metabolism, 16, 430-446.

Kamber, M., Koster, M., Kreis, R., Walker, G., Boesch, C., \& Hoppeler, H. (1999). Creatine supplementation-Part I: Performance, clinical chemistry, and muscle volume. Medicine and Science in Sports and Exercise, 31(12), 1763-1769.

Kresta, J.Y., Oliver, J.M., Jagim, A.R., Fluckey, J., Riechman, S., Kelly, K., ..., \& Kreider, RB. (2014). Effects of 28 days of beta-alanine and creatine supplementation on muscle carnosine, body composition and exercise performance in recreationally active females. Journal of the International Society of Sports Nutrition, 11, article no. 55. doi: 10.1186/s12970-014-0055-6

Mendez-Villanueva, A., Hamer, P., \& Bishop, D. (2007). Fatigue responses during repeated sprints matched for initial mechanical output. Medicine and Science in Sports and Exercise, 39, 2219-2225. doi: 10.1249/ mss.0b013e31815669dc

Okudan, N., Belviranli, M., Pepe, H., \& Gökbel, H. (2015). The effects of beta alanine plus creatine administration on performance during repeated bouts of supramaximal exercise in sedentary men. Journal of Sports Medicine and Physical Fitness, 55(11), 1322-1328.

Saunders, B., Sale, C., Harris, R., \& Sunderland, C. (2012). Effect of beta-alanine supplementation on repeated sprint performance during the Loughborough Intermittent Shuttle Test. Amino Acids, 43, 39-47. doi: 10.1007/s00726012-1268-0

Spencer, M., Bishop, D., Dawson, B., \& Goodman, C. (2005). Physiological and metabolic responses of repeated-sprint activities. Sports Medicine, 35(12), 1025-1044.

Spriet, L.L., Lindinger, M.I., McKelvie, R.S., Heigenhauser, G.J., \& Jones, N.L. (1989). Muscle glycogenolysis and H+ concentration during maximal intermittent cycling. Journal of Applied Physiology, 66(1), 8-13. 
Sweeney, K.M., Wright, G.A., Brice, A.G., \& Doberstein, S.T. (2010). The effect of beta-alanine supplementation on power performance during repeated sprint activity. Journal of Strength and Conditioning Research, 24, 79-87. doi: 10.1519/JSC.0b013e3181c63bd5

Tobias, G., Benatti, F.B., de Salles Painelli, V., Roschel, H., Gualano, B., Sale, C., ..., \& Artioli, G.G. (2013). Additive effects of beta-alanine and sodium bicarbonate on upper-body intermittent performance. Amino Acids, 45(2), 309-317. doi: 10.1007/s00726-013-1495-z

van Loon, L.J.C., Oosterlaar, A.M., Hartgens, F., Hesselink, M.K.C., Snow, R.J., \& Wagenmakers, A.J.M. (2003). Effects of creatine loading and prolonged creatine supplementation on body composition, fuel selection, sprint and endurance performance in humans. Clinical Science, 104(2), 153-162. doi: 10.1042/CS20020159

Yquel, R.J., Arsac, L.M., Thiaudiere, E., Canioni, P., \& Manier, G. (2002). Effect of creatine supplementation on phosphocreatine resynthesis, inorganic phosphate accumulation and $\mathrm{pH}$ during intermittent maximal exercise. Journal of Sports Sciences, 20(5), 427-437. doi: 10.1080/026404102317366681

Ziegenfuss, T., Rogers, M., Lowery, L., Mullins, N., Mendel, R., Antonio, J., \& Lemon, P. (2002). Effect of creatine loading on anaerobic performance and skeletal muscle volume in NCAA Division I athletes. Nutrition, 18, 397-402.

Zoeller, R.F., Stout, J.R., O'Kroy, J.A., Torok, D.J., \& Mielke, M. (2007). Effects of 28 days of beta-alanine and creatine monohydrate supplementation on aerobic power, ventilatory and lactate thresholds, and time to exhaustion. Amino Acids, 33, 505-510. doi: 10.1007/s00726-006-0399-6

Submitted: October 2, 2018

Accepted: October 10, 2018

Published Online First: May 15, 2020

Corresponding author:

Anne Delextrat, Ph.D.

Movement Science Group, Oxford Brookes University

Gipsy lane, Oxford OX3 0BP, United Kingdom

Email: adelextrat@brookes.ac.uk.

Tel: +44 (0) 1865483610

Fax: +44 (0) 1865483242

\section{Acknowledgment, authorships and declarations.}

The authors would like to thank all participants for their time. This research was not funded. There were no conflicts of interest. 